\title{
Reflexões e expectativas iniciais de licenciandos de Ciências da Natureza no ingresso em curso de extensão sobre Educação Emocional e Educação Científica
}

\section{Initial reflections and expectations of undergraduate students of Natural Sciences when entering an extension course on Emotional Education and Science Education}

\author{
Cecilia Decarli (cecilia.decarli@ufrgs.br) \\ Doutoranda no PPG em Educação em Ciências: Química da Vida e Saúde - Universidade Federal do Rio \\ Grande do Sul (UFRGS)
}

Cíntia Inês Boll (cintia.boll@ufrgs.br)

Professora Doutora no PPG em Educação em Ciências: Química da Vida e Saúde - Universidade Federal do Rio Grande do Sul (UFRGS)

Resumo: A Educação Emocional permeia todo o currículo escolar. Uma vez que as emoções norteiam as relações humanas, compreendê-las favorece o desenvolvimento cognitivo, pois gera ações de autocontrole, autoconhecimento e tomada de decisões, também oferecendo subsídios para a Educação Científica de qualidade. Este artigo tem por objetivo identificar as expectativas e reflexões iniciais dos cursistas acerca de um curso de extensão sobre Educação Emocional e Educação Científica, visando construir o planejamento do curso e comparar as expectativas iniciais com a autoavaliação final dos cursistas formados. Foi utilizada a metodologia de análise de conteúdo textual para avaliar respostas de 29 inscritos no curso de extensão mencionado, oriundos da Licenciatura em Ciências da Natureza (UFRGS). Foram geradas análises simples nuvem de palavras e análises multivariadas - e Classificação Hierárquica Descendente (CHD). A partir disso, foi possível inferir sobre classes de palavras e planejar a súmula de conteúdos baseada nas expectativas dos cursistas que, por fim, foram comparadas à autoavaliação final dos alunos concluintes. Essa ferramenta de análise inicial, em conjunto com a avaliação final, demonstrou que trabalhar nessa perspectiva gera qualidade e sucesso a ações de extensão que complementam a formação inicial de professores.

Palavras-chave: Educação Emocional; Educação Científica; extensão; Avaliação.

Abstract: Emotional Education permeates the entire school curriculum. Since emotions guide human relationships. Comprehending them favors cognitive development, as they generate actions of self-control, self-knowledge and decision-making, also offering subsidies for quality scientific education. This article aims to identify initial expectations and reflections about an extension course on Emotional Education and Science Education by the course participants, aiming to build the course planning and compare the initial expectations with the final self-assessment of the trained course participants. The textual content analysis methodology was used to evaluate responses from 29 enrolled in the extension course mentioned, from the licentiate Degree in Natural Sciences (UFRGS).Simple analyzes were generated - word cloud and Recebido em: 18/01/2021

Aceito em: 24/02/2021 
multivariate analyzes - and Descending Hierarchical Classification (CHD). From this, it was possible to infer about word classes and plan the summary of contents based on the expectations of the course participants, which, finally, were compared to the final selfassessment of the graduating studentsThis initial analysis tool, together with the final evaluation, demonstrated that working from this perspective generates quality and success to extension actions that complement the initial teacher education.

Keywords: Emotional Education; Scientific Education; extension; Evaluation.

\section{INTRODUÇÃO}

Este artigo constitui-se de uma análise sobre um projeto de extensão voltado para professores em formação inicial, para auxiliar a propor conteúdos com base na vivência e nas expectativas dos próprios cursistas e realizar uma avaliação final da estratégia. Para tal, discorremos sobre os tópicos: escolha por um curso de nível de extensão para este público, os temas principais abordados no curso em questão, a Educação Emocional e a Educação Científica, a escolha de um recurso pedagógico coletivo para uso em sala de aula e a relação entre os temas elencados na extensão e o objetivo de análise proposto neste estudo.

Cursos de extensão, como denominamos, são aqueles que complementam o conhecimento em áreas especificas. A Lei de diretrizes e Bases da EducaçãoLDB/9.394 afirma, no artigo 44, que a educação superior deve abranger cursos e programas de extensão (BRASIL, 1996). O artigo 61 da mesma lei esclarece como deve ser a formação de professores:

I - a presença de sólida formação básica, que propicie o conhecimento dos fundamentos científicos e sociais de suas competências de trabalho; (Incluído pela Lei $n^{\circ} 12.014$, de 2009)

II - a associação entre teorias e práticas, mediante estágios supervisionados e capacitação em serviço; (Incluído pela Lei no 12.014, de 2009)

III - o aproveitamento da formação e experiências anteriores, em instituições de ensino e em outras atividades. (Incluído pela Lei $n^{\circ} 12.014$, de 2009).

A Resolução CNE/CP1 (BRASIL, 2002), artigo terceiro, afirma que a formação de professores de diferentes etapas e modalidades da educação básica deve ser norteada por princípios que preparem para o exercício profissional, sendo eles:

I - a competência como concepção nuclear na orientação do curso;

II - a coerência entre a formação oferecida e a prática esperada do futuro professor $[. .$.$] ;$

III - a pesquisa, com foco no processo de ensino e de aprendizagem, uma vez que ensinar requer tanto dispor de conhecimentos e mobilizá-los para a ação 
Edição Especial: I SSAPEC - Simpósio Sul-Americano de Pesquisa em Ensino de Ciências

como compreender o processo de construção do conhecimento (BRASIL, 2002).

Síveres (2013, p. 31) define extensão universitária “como um processo de aprendizagem que reafirma o seu caráter acadêmico e viabiliza um percurso para que os projetos de ensino e de pesquisa revelem a possibilidade de um trabalho indissociável". Seguindo este caráter, um projeto de extensão deve levar em consideração as práticas profissionais dos cursistas e a disseminação de saberes perante a sociedade.

Com base na legislação vigente para o ensino superior, que coloca o desenvolvimento de projetos de extensão como função social das instituições, e nos estudos relacionados ao tema deste projeto de extensão apresentados acima, fundamentamos um curso de extensão que realmente fizesse sentido na formação dos cursistas enquanto futuros professores. Estes, através de práticas relacionadas à Educação Emocional, vão disseminar os seus conhecimentos em prol da comunidade escolar em que forem atuar.

Freire (2006), em sua obra Extensão ou comunicação, faz uma crítica à extensão que "coisifica" os sujeitos envolvidos, referindo-se ao poder autoritário que as instituições de ensino superior podem ter ao planejarem suas ações desconhecendo a cultura e o saber popular.

O contato dos licenciandos em Ciências da Natureza com reflexões e análises de situações reais, proporcionadas no projeto de extensão, os propicia compreender situações do ambiente escolar e gera enfoque no trabalho docente interdisciplinar. Cunha e Krasilchik (2000) inferem sobre a importância do currículo dos cursos de licenciatura em Ciências possuírem caráter interdisciplinar, fazendo oposição ao método fragmentado de ensino. Segundo Diniz; Jacques e Galieta (2019), os cursos de Ciências e Biologia precisam criar espaços que propiciem aos licenciandos (re)pensar os processos avaliativos, nesse sentido, foi pensado no tema Educação Emocional em contexto com a Educação Científica.

As emoções fazem-se necessárias para as tomadas de decisão. São oriundas de reações e acontecimentos que surgem inesperadamente e têm uma breve duração. Quando nos emocionamos, transmitimos a evidência disso para o exterior, seja por meio de expressão facial, do tom de voz ou de movimentos corporais (DAMÁSIO, 2001). A Educação Emocional surge como reguladora das emoções e como autoconhecimento, ao possibilitar ao indivíduo educar-se emocionalmente (CASASSUS, 2009). 
Atualmente, a Base Nacional Comum Curricular (BNCC) estabelece 10 competências gerais e habilidades específicas para serem abordadas no currículo escolar nas diferentes áreas de conhecimento. Entre elas, a competência emocional está relacionada a lidar com as emoções, com o ganhar e o perder, aprender com o erro, desenvolver autoconfiança, autoavaliação e responsabilidade (BRASIL, 2019).

Vale (2009 apud BISQUERRA, 2000; GOLEMAN, 1997; VALLÉS; VALLÉS, 2000) analisa programas de educação socioemocional e agrupa cinco objetivos sobre a importância da temática no currículo escolar:

1. Autoconsciência emocional: adquirir um melhor conhecimento das próprias emoções, reconhecer as diferenças entre sentimentos e ações e compreender as causas dos sentimentos;

2. Gestão das emoções: desenvolver habilidades para controlar as próprias emoções, prevenir os efeitos prejudiciais das emoções negativas (por exemplo, melhorar a capacidade para expressar verbalmente a ira sem lutar), desenvolver habilidades de resistência à frustração, desenvolver habilidades para gerar emoções positivas;

3. Controlar produtivamente as emoções: desenvolver habilidades de automotivação, maior capacidade de concentração nas tarefas e maiores responsabilidades, desenvolver a capacidade de saber esperar por recompensas a longo prazo em detrimento de recompensas imediatas;

4. Empatia: desenvolver a capacidade de aceitar a perspectiva do outro, desenvolver sentimentos de empatia e sensibilidade com os outros, e desenvolver a capacidade de escuta;

5. Gerir relacionamentos: desenvolver competências para resolver conflitos e negociar acordos, desenvolver a capacidade de cooperação, de partilha e de ajuda (VALE, 2009, p. 131, apud BISQUERRA, 2000; GOLEMAN, 1997; VALLÉS;VALLÉS, 2000).

Nesse sentido, trabalhar as competências socioemocionais no currículo escolar de maneira interdisciplinar faz-se essencial em todas as áreas de conhecimento. No enfoque do ensino de ciências, cabe aos professores das áreas de Ciências da Natureza abordar, por meio das habilidades previstas na BNCC, os saberes da Educação Científica.

Ao discutir a Educação Científica, mencionamos Lavaqui e Batista (2007), que parafraseiam que a presença de recursos científicos e tecnológicos vem gerando necessidades diferenciadas em relação ao ensino na forma como vem sendo abordado. Muitos desses debates são em relação à Educação Científica e o quanto ela prepara os alunos para o real exercício de cidadania. Isso nos leva a uma reflexão em relação à adoção de práticas interdisciplinares na área de Ciências da Natureza como uma das possibilidades para sua melhoria. 
A alfabetização científica e tecnológica, no sentido atribuído por Fourez (1997, p. 23), propõe-se a "divulgar conhecimentos suficientes para a população de maneira que as decisões dos técnicos possam ser suficientemente compreendidas e também controladas democraticamente". Por sua vez, no entendimento de Batista e Salvi (2006), os estudos interdisciplinares são uma forma de promover o entendimento da pluralidade e da complexidade das relações presentes na atualidade no processo de ensino e de aprendizagem escolares.

O projeto de extensão discutido neste trabalho foi elaborado no intuito de fazer com que os cursistas tivessem noções dos conceitos de Educação Emocional e criassem subsídios para abordá-la no contexto da Educação Científica. Assim, a avaliação final do curso foi a construção coletiva de um Recurso Educacional Aberto (REA).

Segundo a UNESCO (2012), os REA são materiais utilizados no processo de ensino e aprendizagem que possuem domínio público e licença aberta, podendo ser utilizados, adaptados e disseminados por qualquer pessoa. A lei $\mathrm{n}^{\circ} 13.005$ de 25 de junho de 2014 (BRASIL, 2014) prevê, na estratégia 7.12, incentivo para criar, selecionar e certificar tecnologias para atender os objetivos da educação básica, citando a importância de práticas inovadoras e enfatizando a preferência por softwares livres e REAs.

Os REAs potencializam o trabalho colaborativo em rede, qualificam as práticas pedagógicas, permitem compartilhar e recriar situações de ensino-aprendizagem e promovem a socialização de materiais livres e abertos na internet (JACQUES, 2017). Atualmente, percebemos que muitas empresas de consultoria educacional comercializam materiais referentes à Educação Emocional. Sendo assim, criar e remixar REA na área é uma tarefa importante para que os professores atuantes tenham subsídios e recursos para a aplicação do tema em suas aulas.

Este estudo tem por objetivo identificar as expectativas e as reflexões iniciais acerca de um curso de extensão sobre Educação Emocional e Educação Científica, utilizá-las para construir o planejamento do curso de extensão e relacionar as expectativas iniciais com a autoavaliação final dos cursistas formados. A seguir, serão apresentados brevemente os temas propostos no projeto de extensão analisado neste artigo e será especificada a forma como ocorreu a escolha pela extensão para trabalhar estes temas. 


\section{METODOLOGIA}

Este artigo é um recorte de um curso de extensão ministrado para licenciandos do curso de graduação em Ciências da Natureza na modalidade licenciatura. O curso ocorreu de 10 de setembro a 10 de dezembro de 2020, na modalidade EAD, com onze encontros síncronos, encontros assíncronos e a realização de tarefas que totalizaram 60 horas (tabela 1). Realizamos uma análise inicial das reflexões e do que desejavam os cursistas no momento da escolha e da inscrição no curso, pois consideramos este momento essencial para o sucesso de um curso de extensão. A súmula exposta foi construída após esta análise e flexibilizada durante seu desenvolvimento de acordo com as demandas que surgiram a partir dos cursistas.

Tabela 1- Súmula de conteúdos desenvolvidos no curso de extensão.

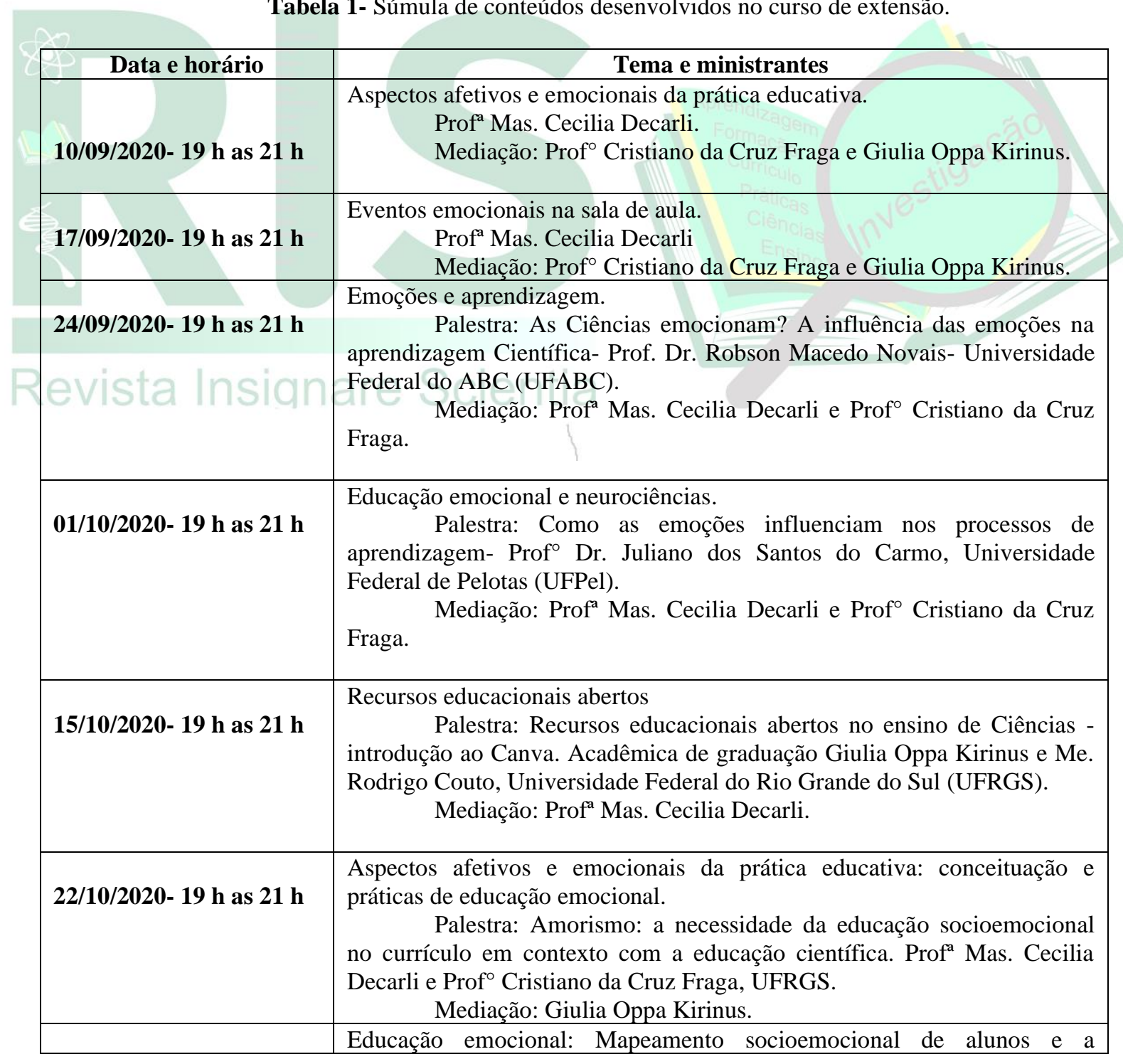




\begin{tabular}{|c|c|}
\hline $29 / 10 / 2020-19 h$ as $21 \mathrm{~h}$ & $\begin{array}{l}\text { importância das competências socioemocionais no currículo escolar. } \\
\text { Produção de REA na Educação Emocional: tarefa guiada e } \\
\text { relacionada a Educação Científica. } \\
\text { Prof }{ }^{\text {a }} \text { Mas. Cecilia Decarli e Giulia Oppa Kirinus. } \\
\text { Mediação: Prof }{ }^{\circ} \text { Cristiano da Cruz Fraga. }\end{array}$ \\
\hline $12 / 11 / 2020-19 \mathrm{~h}$ as $21 \mathrm{~h}$ & $\begin{array}{c}\text { Orientação sobre produção de REA. } \\
\text { Giulia Oppa Kirinus. }\end{array}$ \\
\hline 19/11/2020- $19 \mathrm{~h}$ as $21 \mathrm{~h}$ & $\begin{array}{l}\text { Comunicação afetiva com crianças e jovens, Cultura da Paz, prevenção de } \\
\text { suicídio e depressão por meio do trabalho emocional. } \\
\text { Palestra: Projeto Escola da Vida, relatos de práticas } \\
\text { socioemocionais na escola. } \\
\text { Prof Jelson Olacir Pereira, Muriel Passini e Ester Beck. } \\
\text { Mediação: Mas. Cecilia Decarli e Prof }{ }^{\circ} \text { Cristiano da Cruz Fraga. }\end{array}$ \\
\hline $26 / 11 / 2020-19 \mathrm{~h}$ as $21 \mathrm{~h}$ & $\begin{array}{l}\text { Recursos educacionais abertos: conceitos, licenças e construção. } \\
\text { Análise textual de artigos nacionais de Educação Emocional e } \\
\text { suas potencialidades em relação ao FIB (Índice de Felicidade Interna } \\
\text { Bruta). } \\
\text { Prof }{ }^{\text {a }} \text { Mas. Cecilia Decarli e Giulia Oppa Kirinus. } \\
\text { Mediação: Prof }{ }^{\circ} \text { Cristiano da Cruz Fraga. }\end{array}$ \\
\hline $10 / 12 / 2020-19 \mathrm{~h}$ as $21 \mathrm{~h}$ & $\begin{array}{l}\text { Apresentação dos REAs de Educação Emocional e Educação Científicos } \\
\text { criados pelos cursistas. } \\
\text { Prof }{ }^{\text {a }} \text { Mas. Cecilia Decarli e Giulia Oppa Kirinus. }\end{array}$ \\
\hline
\end{tabular}

Fonte: Elaborado pelas autoras (2021).

Partimos das respostas dos 29 inscritos no curso de extensão denominado "A Educação Emocional e a Educação Científica: criando competências socioemocionais com Recursos Educacionais Abertos (REA) nas disciplinas de Ciências da Natureza”. Essas pessoas eram alunos de licenciatura em Ciências da Natureza dos polos da Universidade Aberta do Brail (UAB )de Novo Hamburgo, Imbé, Santo Antônio da Patrulha e Porto Alegre, da Universidade Federal do Rio Grande do Sul (UFRGS).

As respostas analisadas foram referentes à questão: Justifique o porquê deseja cursar este curso de extensão, o que entende por Educação Emocional nas escolas e responda se você tem interesse em produzir um REA na área de Educação Emocional e Educação Científica? Como você vê essa contribuição como licenciando (a) e futuro professor (a)?

Como critério, as respostas não podiam ultrapassar 1000 caracteres, o que garantiu um material mais uniforme para a análise textual. O método utilizado foi de análise de conteúdo (BARDIN, 1977), com análise textual através do software IRAMUTEQ, que é gratuito e foi desenvolvido sob a lógica da open source, licenciado por GNU GPL (v2). Ele ancora-se no ambiente estatístico do software R e na linguagem python (CAMARGO; JUSTO, 2018). 
Edição Especial: I SSAPEC - Simpósio Sul-Americano de Pesquisa em Ensino de Ciências ISSN: 2595- $4520 \quad$ Vol. 4, n. 3. 2021

Foi produzido um corpus textual com as 29 respostas e, então, gerou-se uma nuvem de palavras. A partir dela, foi analisada a frequência das palavras nas respostas dos cursistas e feita uma análise de Classificação Hierárquica Descendente (CHD) conforme proposto por Reinert (1990). Foi utilizado o software ALCESTE, que classifica os segmentos de texto em função dos seus respectivos vocabulários, e o conjunto deles é repartido com base na frequência das formas reduzidas (palavras já lematizadas). Esta análise visa obter classes de Unidade de contexto elementar- (UCE) que, ao mesmo tempo, apresentam vocabulário semelhante entre si e vocabulário diferente das UCE de outras classes.

Assim, foi possível investigar a frequência de palavras nas respostas e classificálas de acordo com as classes de palavras. Dessa forma, foi evidenciando o interesse dos cursistas por assuntos (representados em nomes de classes).

Os dados obtidos foram analisados e a nuvem de palavras foi apresentada ao grupo de cursistas na primeira aula. A súmula de conteúdos foi criada e, ao longo do curso, modificada, levando em consideração o interesse dos alunos envolvidos. Como desfecho do curso, os alunos preencheram um questionário abrangendo a autoavaliação. Isso nos permitiu elencar dados de satisfação em relação ao curso ministrado e verificar se as expectativas iniciais foram correspondidas. Estes dados também foram registrados neste artigo por meio de gráficos e textos posteriormente discutidos.

\section{RESULTADOS E DISCUSSÕES}

A análise textual do software IRAMUTEQ foi feita com 29 textos de respostas dos cursistas e resultou em 2403 ocorrências, 604 formas e 335 palavras hápax (que aparecem uma única vez), com 82,86\% de significado total na análise.

A partir disso, geramos uma nuvem de palavras. As que tiveram ocorrência maior que 10 vezes foram: emocional, curso, aluno, educação, professor, aprender, emoção, conhecimento, lidar, escola, desenvolver e extensão (figura 1). Os termos demonstram interesse no tema Educação Emocional e no trabalho dela em sala de aula, havendo uma preocupação com a aprendizagem sobre emoções. 


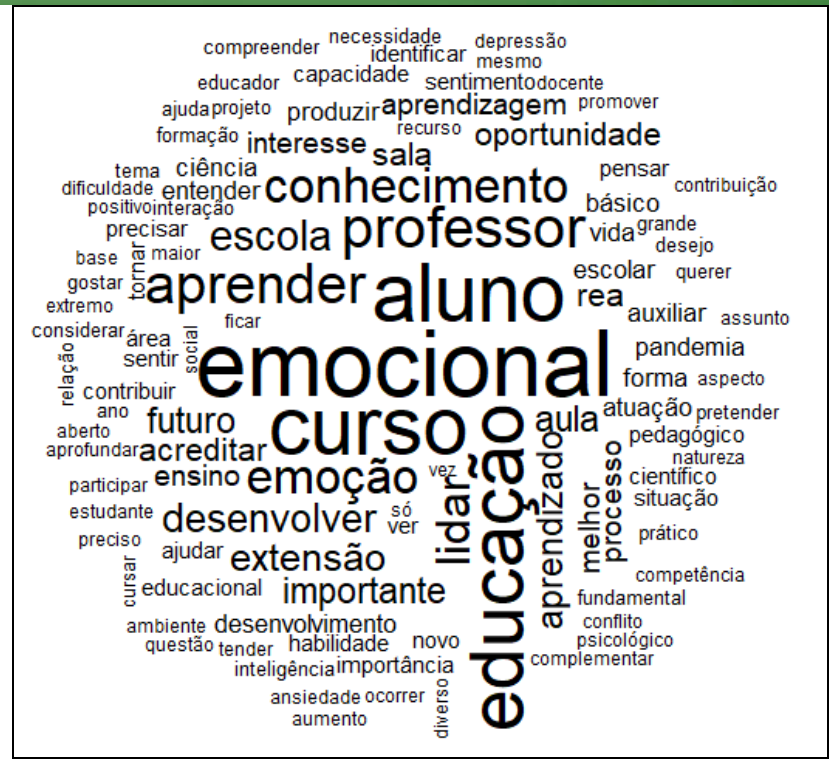

Figura 1 - Nuvem de palavras.

Fonte: Elaborado pelas autoras (2021).

O curso de extensão busca oportunizar que as teorias reflitam e resultem em transformações sociais, com intuito de melhorar o ensino e aprendizagem. Assim, novos conhecimentos são apresentados aos cursistas, fazendo com que ampliem suas perspectivas sobre melhorias na educação básica e superior (MAZZILLI, 2011). Demonstrou-se uma iniciativa muito útil compreender, por meio de análises iniciais simples, o que o cursista almeja ao buscar cursos de extensão, proporcionando uma construção conjunta.

$\mathrm{Na}$ análise de CHD, as classes 1 e 4 se mostraram relacionadas e 2 e 3 também, apresentando distinção com relação à classe 5 (figura 2).

Classe 1: Educação Emocional - 22,7\% dos cursistas estavam preocupados com a aprendizagem em relação à Educação Emocional, ao desenvolvimento de sentimentos e ao conhecimento para lidar com Educação Emocional no ambiente da sala de aula.

Classe 2: Participação em relação ao tema - $18,2 \%$ consideraram muito importante a temática oferecida pelo curso, por intermédio de sua descrição prévia.

Classe 3: Inteligência emocional - 15,9\% consideraram a área da inteligência emocional e os processos psicológicos envolvidos relevantes ao contexto pedagógico. 
Classe 4: Identificação das emoções - 22,7\% consideraram relevante a aprendizagem mediada pelas emoções, assim como a identificação e atuação no campo educacional em relação as emoções.

Classe 5: Oportunidade de Extensão - 20,4\% elencam o curso como uma oportunidade e um auxílio para desenvolver e executar projetos em sala de aula.

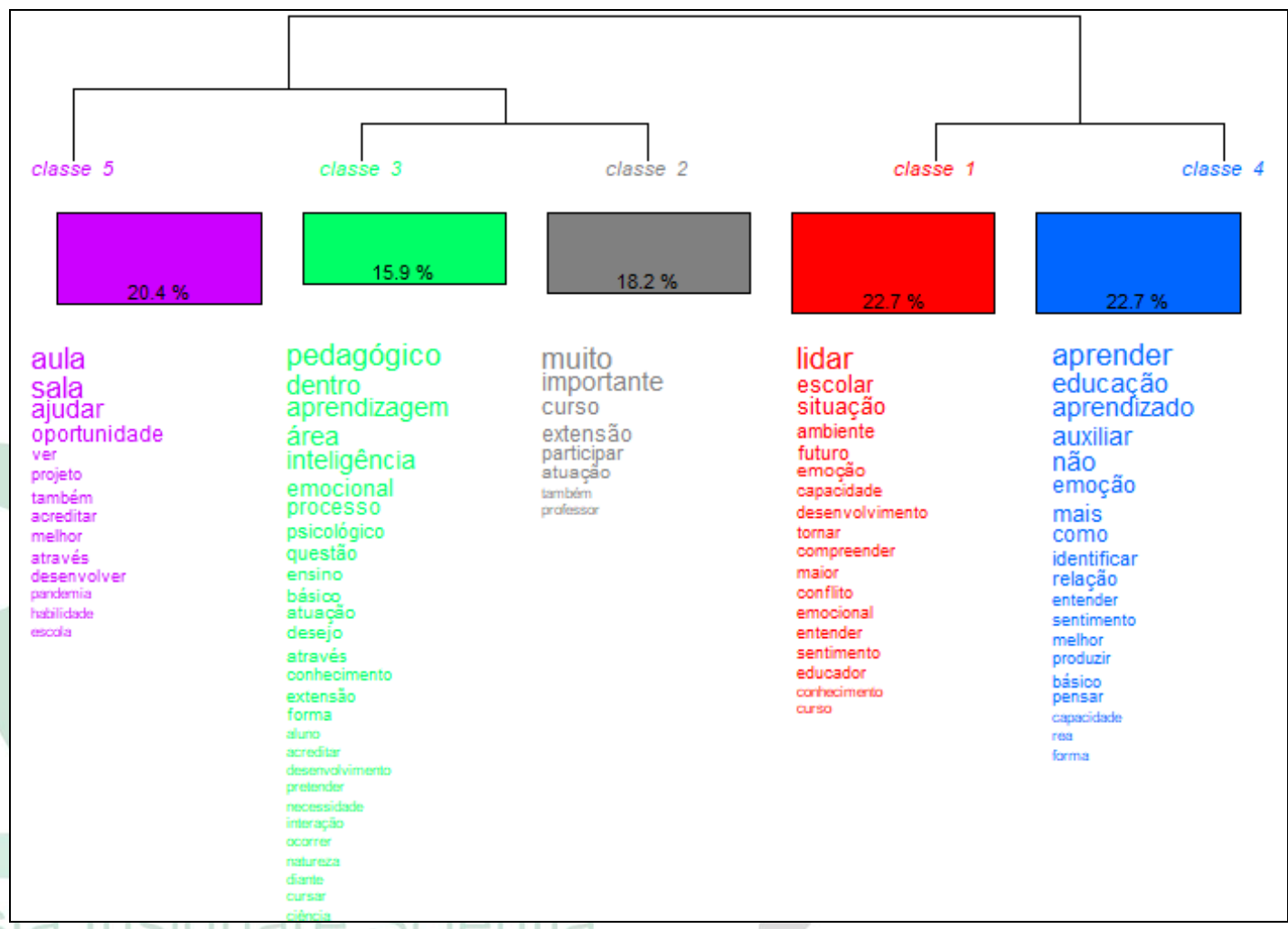

Figura 2 - Análise de Classificação Hierárquica Descendente (CHD).

Fonte: Elaborado pelas autoras (2021).

Os cursistas, em maioria, relataram por meio de reflexões em considerações iniciais que consideram importante o tema Educação Emocional para as futuras práticas docentes. Ademais, demonstraram interesse em aprender sobre emoções e sentimentos e sua abordagem em sala de aula, elencaram os processos psicológicos relacionados e $20 \%$ mencionam uma oportunidade de extensão para o currículo.

Partindo das ideias expostas pela frequência de palavras na nuvem e pelas classes geradas através do software IRAMUTEQ, é possível perceber que os cursistas ingressaram no curso de extensão para aprender e utilizar a Educação Emocional nas suas práticas científicas nas aulas de Ciências da Natureza. 
Edição Especial: I SSAPEC - Simpósio Sul-Americano de Pesquisa em Ensino de Ciências ISSN: 2595- $4520 \quad$ Vol. 4, n. 3. 2021

A Educação Científica apareceu com baixa frequência na nuvem de palavras e está inserida de forma condensada nas classes geradas. Ressaltamos que os cursistas vêm da graduação em licenciatura em Ciências da Natureza e, provavelmente, já têm uma carga de conteúdo na formação inicial relacionada à Educação Científica. Dessa forma, necessitando mais da formação em relação à Educação Emocional e à ligação entre ambas.

Andrade, Morosini e Lopes (2019) elencam em seus estudos o conceito de universidade do encontro, que através da interpretação de dados de entrevistas com docentes de extensão, identificaram traços referentes à ampliação dos espaços integradores da universidade que são fortalecidos pela relação ensino, pesquisa e extensão, advindos de práticas pedagógicas renovadas no ensino superior, no qual a integração entre conhecimentos científicos e experiência fortalece o surgimento do aluno e do professor reflexivo e pesquisador. Esse viés vem ao encontro da proposta deste estudo, de identificar as expectativas iniciais do cursista de extensão em relação a sua formação inicial a fim de complementar sua formação acadêmica e profissional e criar um vínculo positivo e produtivo com o aluno.

Dos 29 alunos ingressantes, 21 concluíram. Esses alunos participaram no mínimo em 75\% dos encontros síncronos previstos (11 encontros síncronos e atividades assíncronas), realizaram mais de $75 \%$ das tarefas assíncronas propostas no Moodle, $100 \%$ participaram da entrevista inicial e $62 \%$ (18 pessoas) da autoavaliação final do curso. Todos participaram dos debates sobre o tema nas aulas síncronas, no Moodlee no Whatsapp e $100 \%$ dos concluintes criaram e apresentaram seu REA como produção final e avaliativa, que depois foi adaptada a uma produção coletiva.

Em relação à autoavaliação final preenchida por $86 \%$ dos cursistas que concluíram com êxito o curso (que representam 62\% dos persistentes e concluintes do curso), verificamos que a análise inicial foi um instrumento que desencadeou sucesso 
nas ações de extensão, conforme demonstrado no gráfico (figura 3) e no texto abaixo.

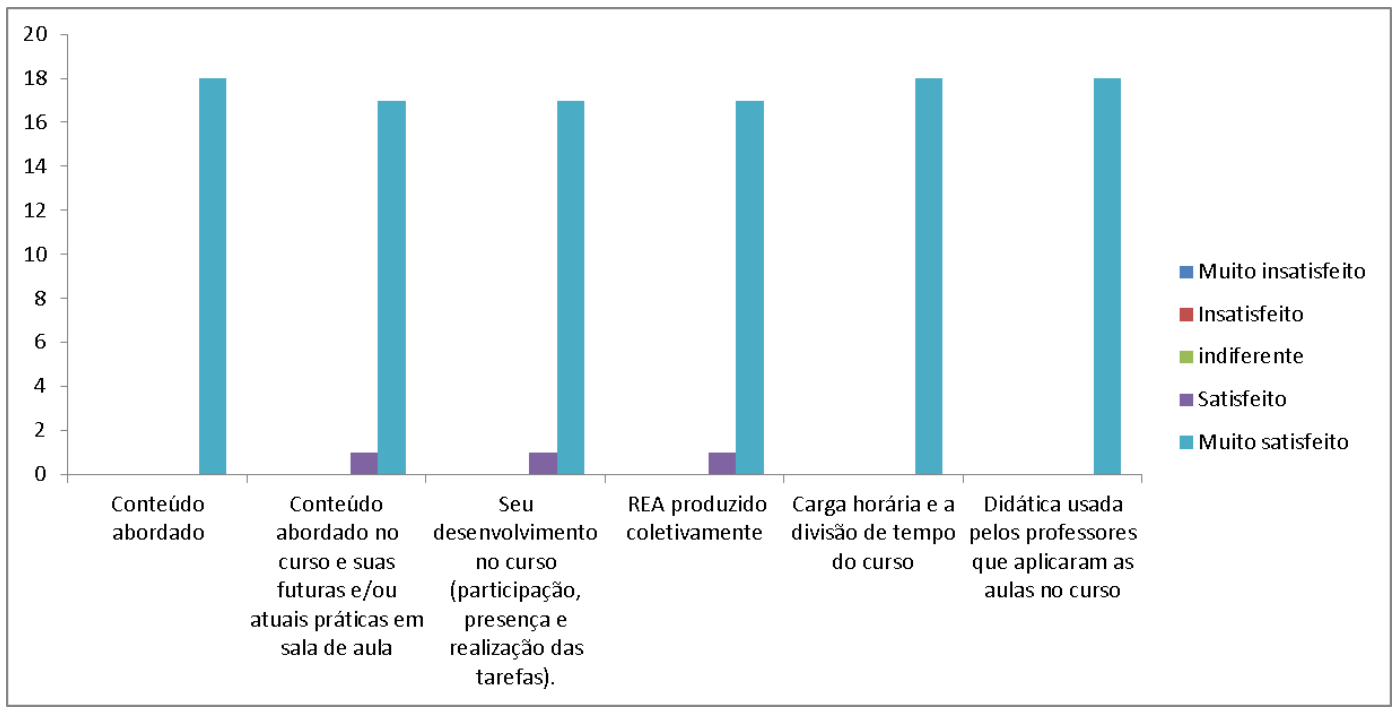

Figura 3 - Nível de satisfação dos alunos cursistas concluintes do curso de extensão.

Fonte: Elaborado pelas autoras (2021).

Atribuímos o êxito e a permanência dos cursistas na extensão proposta, ao modelo de planejamento elaborado, que além de ser flexível e considerar o que os cursistas desejavam aprender sobre o tema proposto, também oportunizou uma avaliação contínua e com uma produção coletiva como desfecho. Segundo Diniz; Jacques e Galieta (2019), a avaliação não deve promover exclusão nem opressão, já que não deve ser vista apenas como um produto final, mas sim ser contínua e formativa, tornando-se parte fundamental do processo de ensino-aprendizagem.

Em relação à questão dissertativa sobre o que os alunos mais gostaram no curso, enfatizamos a presença do conteúdo Educação Emocional em todas as respostas, além de elogios às palestras, dinâmicas, experiências compartilhadas, tecnologias utilizadas e à condução didática, explícitos em comentários como os selecionados, abaixo:

CURSISTA 1 - "A possibilidade de conhecer mais sobre Educação Emocional. Aprender que antes de qualquer didática aplicada em sala de aula, reconhecer e respeitar os sentimentos dos alunos é o mais importante. Gostei de conhecer a Cecilia, o Cristiano e a Giulia, o carinho e a atenção deles em todo o desenvolvimento do curso, fez eu me sentir acolhida."

CURSISTA 2 - "Dos diálogos, do compartilhamento das experiências, das palestras, apresentação de mídias digitais que não conhecia. Gostaria de afirmar que a partir do curso pude compreender o verdadeiro papel do professor, além de mediador da construção do processo de ensino- 
aprendizagem o papel de ator-social que é fundamental para uma educação mais humanizadora."

CURSISTA 3 - "Gostei de tudo na verdade, kkkk. Os professores, o conteúdo tanto na abordagem emocional como científica, os depoimentos de todos, a afetividade presente em cada aula."

Quando questionados sobre o que não gostaram no curso e as dificuldades, não houve relatos do que não gostaram. Seis cursistas relataram dificuldades com as tecnologias, mas todos comentaram que foram sanadas ao longo do curso.

Por fim, os cursistas sugeriram a elaboração de um novo módulo do mesmo curso e a adaptação para uma disciplina integrante da grade curricular do próprio curso de licenciatura. Arroyo e Rocha (2010) concluíram através de um estudo de caso que as instituições de ensino superior tem demonstrado cada vez mais interesse no debate sobre avaliação institucional que envolve projetos de extensão e vem encontrando espaço satisfatório em eventos de divulgação científica, já que este processo valoriza a participação dos sujeitos envolvidos tornando a avaliação crítica e reflexiva.

Os cursistas participaram da ação de extensão desde sua construção até seu desfecho, o que os fez protagonistas na busca por conhecimento. Segundo Síveres (2013), a participação de professores e alunos em processos de extensão oportuniza uma transformação social, pois através da participação ativa o cursista pode vivenciar como será o ambiente de sua futura atuação profissional e contar com um complemento de qualidade para sua formação acadêmica integral.

Os dados expostos na autoavaliação final demonstram que o curso atingiu plenamente os objetivos para os concluintes, tornando-se uma formação extensionista complementar à formação inicial e importante para futuros professores. O processo foi norteado pelas expectativas iniciais dos próprios cursistas, que foram protagonistas desde o ingresso na extensão até o desfecho com a construção coletiva do REA.

\section{CONSIDERAÇÕES FINAIS}

O conhecimento abordado em cursos de extensão não pode ser apenas transmitido. É necessário que haja uma construção coletiva entre os participantes, levando em consideração o diálogo, as vivências e cultura dos envolvidos, pois isso torna os cursistas sujeitos ativos do processo. Portanto, não deve haver espaço para 
Edição Especial: I SSAPEC - Simpósio Sul-Americano de Pesquisa em Ensino de Ciências

ISSN: 2595- $4520 \quad$ Vol. 4, n. 3. 2021

superioridade de quem ministra. Freire (2006) argumenta que se transformarmos o homem em "coisa" estaremos negando a transformação do mundo. Assim, entendemos que o conhecimento só tem real significado quando aplicado à realidade concreta.

Nesse sentido, a análise prévia dos conhecimentos e das expectativas de cursistas ingressantes no curso de extensão denominado “A Educação Emocional e a Educação Científica: criando competências socioemocionais com REA nas disciplinas de Ciências da Natureza”, apontou que os cursistas gostariam de receber conteúdos referentes à Educação Emocional, focados nas futuras práticas em sala de aula.

A partir da análise textual gerada, foi possível fundamentar e criar objetivos que foram ao encontro do que desejavam os cursistas. Visamos complementar a formação inicial destes licenciandos, oferecer recursos pedagógicos sobre a temática proposta e diminuir o índice de evasão no curso de extensão proposto.

Este recorte de análise do projeto de extensão, desenvolvido com cursistas ainda em formação inicial, demonstra a importância de ações de extensão que complementem o currículo formal da graduação. Dessa forma, alinha-se ao que propõe a BNCC em relação a competências, habilidades e trabalho interdisciplinar na escola, considerando ainda o uso das tecnologias e dando suporte ao futuro professor da área de Ciências da Natureza.

Os resultados expressos por meio da autoavaliação final dos cursistas concluintes demonstram satisfação e permitem aprimorar e qualificar este projeto de extensão para futuras edições do curso. Este estudo torna-se um referencial para outros projetos de extensão que busquem considerar o conhecimento prévio e o protagonismo do cursista durante todo o processo, pois propõe uma ferramenta de análise prévia sobre as expectativas iniciais e uma análise após o término do curso, permitindo comparação com o desfecho do projeto e estimulando a formação continuada de qualidade.

\section{REFERÊNCIAS}

ANDRADE, R.M.M.; MOROSINI, M.C.; LOPES, D.O. A extensão universitária na perspectiva da universidade do encontro. Em aberto. V.32, n 106, 117-131, 2019. Disponível em:

<http://www.emaberto.inep.gov.br/ojs3/index.php/emaberto/article/view/4229> Acesso em 12 fev. 2021. 
ARROYO, D. M. P.; ROCHA, M. S. P. M. L. Meta-avaliação de uma extensão universitária: Estudo de caso. Avaliação: Revista da Avaliação da Educação Superior (Campinas), Sorocaba , v. 15, n. 2, p. 131- 157, 2010 . Disponível em: $<$ http://www.scielo.br/scielo.php?script=sci_arttext\&pid=S1414$40772010000200008 \& \operatorname{lng}=\mathrm{en} \& \mathrm{nrm}=\mathrm{iso}>$. Acesso em 12 fev.2021.

BARDIN, L. Análise de Conteúdo. Lisboa: Edições 70, 1977. 225 p.

BATISTA, I. L.; SALVI, R. F. Perspectiva pós-moderna e interdisciplinaridade educativa: pensamento complexo e reconciliação integrativa. Ensaio, Belo Horizonte, v. 8, n. 2, p. 147-159, 2006. Disponível em: < https://www.scielo.br/scielo.php?script=sci_arttext\&pid=S198321172006000200171\&lng=pt\&tlng=pt> Acesso em 12 fev. 2021.

BRASIL. Lei de Diretrizes e Bases da Educação Nacional. Lei 9.394, de 20 de dezembro de 1996. Estabelece as diretrizes e bases da educação nacional. Brasília, DF, 1996. Disponível em: <http://www.planalto.gov.br/ccivil_03/leis/19394.htm>. Acesso em: 25 dez. 2020.

BRASIL. Resolução CNE/CP1, de 18 de fevereiro de 2002. Institui as Diretrizes Curriculares Nacionais para a formação de professores da educação básica, em nível superior, curso de licenciatura, de graduação plena. Brasília, DF: 2002a. Disponível em: <http://portal.mec.gov.br/cne/arquivos/pdf/CP012002.pdf〉. Acesso em: 5 dez. 2020.

BRASIL. PNE (2014-2024). Lei no 13.005, de 25 de junho de 2014. Aprova o Plano Nacional de Educação-PNE e dá outras providências. Disponível em: <http://www.planalto.gov.br/ccivil_03/_Ato2011-2014/2014/Lei/L13005.htm>. Acesso em 20 dez. 2020.

BRASIL. Base Nacional Comum Curricular: Educação Infantil e Ensino Fundamental. Brasília: MEC/Secretaria de Educação Básica, 2019.

CAMARGO B.V.; JUSTO A. M. Tutorial para uso do software de análise textual IRAMUTEQ. Universidade Federal de Santa Catarina. 2018. Disponível em: <http://iramuteq.org/documentation/fichiers/tutoriel-portugais-22-11-2018> Acesso em 07 set. 2020.

CASASSUS, J. Fundamentos da Educação Emocional. Brasília: UNESCO, Liber Livros, 2009.

CUNHA, A. M. O.; KRASILCHIK, M. A formação continuada de professores de ciências: percepções a partir de uma experiência. In...Ata da $23^{a}$ Reunião Anual da Associação Nacional de Pós-Graduação e Pesquisa em Educação. Caxambu: ANPEd, 2000.

DAMÁSIO, A. O Erro de Descartes: Emoção, Razão e Cérebro humano.

Publicações Europa América, Portugal, 2001.

DINIZ, B.L.T; JACQUES, B.P.; GALIETA, T. Funções da avaliação da aprendizagem na formação inicial de professores de Ciências. Revista Insignare Scientia- RIS, vol. 2, n 2, 166-184, 2019. Disponível em: < https://periodicos.uffs.edu.br/index.php/RIS/article/view/10851> Acesso em 12 fev. 2021.

FREIRE, P. Extensão ou Comunicação. 13a Edição. São Paulo: Paz e Terra. 2006. 
FOUREZ, G. Alfabetización científica y tecnológica: acerca de las finalidades de la enseñanza de las ciencias. Buenos Aires: Ediciones Colihue, 1997.

JACQUES, J.S. Potencialidade dos REA no Ensino-aprendizagem mediado por Tecnologias em Rede. EaD em Foco. v. 7, n. 1, p. 15-26, 2017. Disponível em: < https://eademfoco.cecierj.edu.br/index.php/Revista/article/view/551> Acesso em 12 fev. 2021.

LAVAQUI. V.; BATISTA.I.L. Interdisciplinaridade em ensino de Ciências e de Matemática no Ensino Médio, Ciênc. educ. (Bauru) vol.13 no.3 Bauru, 2007.

Disponível em: < https://www.scielo.br/scielo.php?script=sci_arttext\&pid=S151673132007000300009> Acesso em 12 fev. 2021.

MAZZILLI, S. Ensino, pesquisa e extensão: reconfiguração da universidade brasileira em tempos de redemocratização do Estado. Revista Brasileira de Política e Administração da Educação. RBPAE, v.27, n.2, p. 205-221, 2011.

REINERT, M. Alceste: une méthodologie d'analyse des données textuelles et une application: Aurélia de G. de Nerval. Bulletin de Méthodologie Sociologique, (28), 2454, 1990. Disponível em: < https://www.jstor.org/stable/24362247?seq=1> Acesso em 12 fev. 2021.

SÍVERES, L. (Org.) A extensão universitária como um princípio de aprendizagem. Brasília: Líber Livro, 2013.

UNESCO. Declaração REA de Paris em 2012. Disponível em:

<http://www.unesco.org/new/fileadmin/MULTIMEDIA/HQ/CI/WPFD2009/Portuguese _Declaration.html>. Acesso em 13 dez. 2020.

VALE, V. Do tecer ao remendar: os fios da competência socio-emocional. Exedra, $\mathbf{n}^{\circ}$ 2, 129-146, 2009. Disponível em: < https://docplayer.com.br/20310878-Do-tecer-aoremendar-os-fios-da-competencia-socio-emocional.html> Acesso em 12 dez 2020.

\section{APOIO}

Agradecemos ao PPG em Educação em Ciências: Química da Vida e SaúdeUFRGS, a Pró-Reitoria de Extensão (PROREXT)- UFRGS e ao Instituto de Ciências Básicas da Saúde (ICBS)- UFRGS por possibilitar esta ação de extensão, ao projeto BEINC-PROPESQ-UFRGS pela verba destinada à iniciação científica e aos colegas que colaboraram ministrando as aulas no curso de extensão, Me. Cristiano da Cruz Fraga e Acadêmica Giulia Oppa Kirinus- UFRGS. 